\title{
Pulmonary embolectomy for acute massive pulmonary embolism: an analysis of 71 cases
}

\author{
HUON H GRAY, JOHN M MORGAN, MATTHIAS PANETH, * \\ GRAHAM A H MILLER \\ From the Departments of Cardiology and ${ }^{\star}$ Cardiothoracic Surgery, Brompton Hospital, London
}

SUMMARY Between 1964 and 1986 a total of 71 pulmonary embolectomies were performed for acute massive pulmonary embolism. All patients were severely compromised haemodynamically. $\dot{\omega}$ Sixteen $(64 \%)$ of 25 patients who had sustained significant periods of cardiac arrest before $\vec{\varphi}$ operation died. The principal cause of death in this group was severe neurological damage. Five? $(11 \%)$ of the 46 who had not had a cardiac arrest died. The $50(70 \%)$ patients who survived did so largely without morbidity during their hospital admission and in the follow up period. Most were $\vec{c}$ not treated with long term anticoagulants and only two had another embolism.

When a patient with acute massive pulmonary embolism is too ill to be given thrombolytic treatment, or when thrombolysis is either contraindicated or too slow in producing benefit, pulmonary embolectomy remains an effective alternative treatment with an acceptable mortality.

Acute massive pulmonary embolism is a life threatening disorder that must be treated immediately. Some believe that there are no indications for embolectomy ${ }^{1}$ while others justify prophylactic open embolectomy. ${ }^{2}$ This debate was particularly intense in the early 1970 s once thrombolytic treatment was shown to hasten the resolution of pulmonary emboli. ${ }^{34}$ Although we often use thrombolytic agents to manage patients with acute massive pulmonary embolism we continue to refer patients for pulmonary embolectomy. We report the indications for this operation and our experience of its use in 71 patients.

\section{Patients and results}

Between 1964 and 1986 a total of 139 patients were admitted to the Brompton Hospital with acute massive pulmonary embolism. Until 1968 heparin was the only available drug and therefore all 30 patients with acute massive pulmonary embolism admitted during this period had pulmonary embolectomy. After 1968 streptokinase became available and was

Requests for reprints to Dr Huon H Gray, Department of Cardiology, St George's Hospital, Blackshaw Road, London SW17 0QT.

Accepted for publication 31 May 1988 given to 68 patients, some of whom are described elsewhere. ${ }^{5}$ Although the introduction of thrombolytic treatment reduced the annual number of pulmonary embolectomies this operation was per- $\frac{\mathbb{D}}{\circ}$ formed in 41 of 109 patients with acute massive pulmonary embolism. Sixteen patients $(39 \%)$ had aO definite contraindication to thrombolytic treatment (major surgery within the last week $(n=10)$, pregnancy $(n=2)$, haemorrhagic eye disease $(n=1)$, active gastrointestinal bleeding $(n=1)$, active ulcerative colitis $(n=1)$, and lung cavitation $\stackrel{\varrho}{\rightleftharpoons}$ $(n=1)$ and $13(32 \%)$ were considered to be too ill for a trial of streptokinase. Two patients $(5 \%)$ started on streptokinase but they deteriorated and were referredô for operation. A further five $(12 \%)$ patients had undergone a major operation 8-14 days before their acute massive pulmonary embolism, and in the early days of our experience with thrombolysis we regar-․ㅡ․ ded this as a relative contraindication. In fourN patients $(10 \%)$ thrombolytic treatment could have been given but pulmonary embolectomy was regarded as the best treatment.

So over 23 years 71 pulmonary embolectomies were performed (49 women, mean age 39.4 years, range $17-68$ and 22 men, mean age $51 \cdot 2$ years, range 15-75). All patients had a clinical diagnosis of ${ }^{\text {? }}$ massive pulmonary embolism and an appreciable impairment of haemodynamic function. Twenty five patients $(35 \%)$ had required clinically significant periods of external massage before operation because $\stackrel{\mathbb{Q}}{\circ}$ 
of severe circulatory collapse. The patients' symptoms had started less than 24 hours before in $65 \%$ and between 24 and 48 hours before in $25 \%$. Seven patients $(10 \%)$ had had documented symptoms suggestive of pulmonary emboli for 3-7 days but were referred only when a further acute episode resulted in major deterioration in haemodynamic function.

Potential risk factors for the development of pulmonary emboli included recent operation in 41 patients $(58 \%)$, the contraceptive pill in nine $(13 \%)$, and pregnancy in five $(7 \%)$. Twenty three patients $(32 \%)$ were considered to be too ill to undergo pulmonary angiography and in a further $13(18 \%)$ patients cardiac catheterisation was believed to be unnecessary because the diagnosis of acute massive pulmonary embolism was clinically certain. These 36 patients were referred immediately for operation and in all cases the diagnosis was confirmed then. Thirty five $(50 \%)$ underwent right heart catheterisation. Mean pressures $(\mathrm{mm} \mathbf{H g}$ ) for the group were as follows: right atrium (mean) $=11$, right ventricular systolic $=45$, mean pulmonary artery $=29$. Mean arterial oxygen saturation was $40 \%$ in the pulmonary artery and $86 \%$ in a systemic artery. Pulmonary arteriography was performed in all catheterised patients; this showed pulmonary emboli that occupied $>50 \%$ of the pulmonary arterial tree. There was often a transient worsening of hypotension after the injection of contrast but this resolved rapidly. Three patients $(9 \%)$ required short periods of external cardiac massage ( $<1$ minute) after angiography but were quickly resuscitated and are not included in the group of 25 patients described above who required "considerable" periods of external cardiac massage.

Sixty four $(90 \%)$ of the 71 pulmonary embolectomies were undertaken by one surgeon (MP) and all were performed on full cardiopulmonary bypass. The mean perfusion time was 27 minutes. Four patients were put on partial (femoro-femoral) bypass before the start of full bypass.

\section{DEATHS (TABLE 1)}

Twenty one patients $(29.6 \%)$ died during their hospital admission and 16 of these had required considerable periods of external cardiac massage before operation. Three of these 16 died on bypass, nine died within four weeks with severe neurological damage, three died in the first postoperative week of circulatory or multisystem failure, and one died at five weeks of carcinomatosis. Of the five patients who died without having had preoperative external cardiac massage one died on bypass, one died of pleural bleeding, and one of gastrointestinal bleeding; one patient died within 24 hours of persistent hypotension; and one died at six days after iliocaval thrombectomy for extensive venous occlusion. The
Table 1 Causes of death in patients undergoing pulmonary embolectomy who had had external cardiac massage

( + ECM) before operation and those who had not (-ECM)

\begin{tabular}{|c|c|c|}
\hline Deaths $(21 / 71,29 \cdot 6 \%)$ & $+E C M(\%)$ & $-\operatorname{ECM}\left({ }^{\circ}\right)$ \\
\hline $\begin{array}{l}\text { On cardiopulmonary bypass } \\
\text { Neurological }\end{array}$ & $\begin{array}{l}3(14) \\
9(43)\end{array}$ & $1(5)$ \\
\hline $\begin{array}{l}\text { Circulatory/multisystem failure } \\
\text { Carcinomatosis }\end{array}$ & $\begin{array}{l}3(14) \\
1(5)\end{array}$ & $1(5)$ \\
\hline $\begin{array}{l}\text { Haemorrhage } \\
\text { Massive venous occlusion }\end{array}$ & & $\begin{array}{l}2(10) \\
1(5)\end{array}$ \\
\hline Total & $16(76)$ & $5(24)$ \\
\hline
\end{tabular}

mortality was $64 \%$ in patients who had required preopertive external cardiac massage and $11 \%$ in those who had not.

\section{SURVIVORS (TABLE 2)}

Fifty $(70.4 \%)$ patients survived to leave hospital; nine of them had required preoperative external cardiac massage. One of the 50 survivors needed haemodialysis but then made a full recovery, three had moderate neurological deficits that were thought to have been present before operation, and in one hemiplegia developed after operation. This was thought to have been caused by a paradoxical embolus through a patent foramen ovale.

After discharge from hospital seven $(14 \%)$ patients were lost to follow up but data were available from general practitioner and hospital records on the remaining $43(86 \%)$. Four $(8 \%)$ patients died during follow up, one of carcinoma at 20 months, one of peritonitis at 12.5 years, one after a mitral valve replacement at 15 years, and one patient with nephrotic syndrome died of peritonitis five months after embolectomy. During his terminal illness the last patient had a further pulmonary embolus. We do not know whether he was taking anticoagulants at the time.

The 39 patients who were still alive at the last recorded attendance have been followed up for a total of 335 patient years (mean duration of follow up 94.6 months, range 1-254). All have remained well and in only one patient was there any suggestion of a further

Table 2 Morbidity in patients who survived pulmonary embolectomy and who had had external cardiac massage before operation ( +ECM) and those who had not (-ECM)

\begin{tabular}{lll}
\hline Survivors $(50 / 71,70.4 \%)$ & $+E C M(\%)$ & $-E C M(\%)$ \\
\hline $\begin{array}{lll}\text { Full recovery } \\
\text { Temporary haemodialysis }\end{array}$ & $8(16)$ & $37(74)$ \\
$\begin{array}{l}\text { Moderate neurological damage: } \\
\text { Present before operation }\end{array}$ & $1(2)$ & $1(2)$ \\
$\begin{array}{l}\text { Developed after operation } \\
\text { Total }\end{array}$ & $9(18)$ & $2(4)$ \\
\hline
\end{tabular}


pulmonary embolus. In this patient, who also had nephrotic syndrome, some pleuritic chest pain developed but no other clinical features of pulmonary embolism and he was advised to restart warfarin. Subsequently he remained well.

\section{ANTICOAGULATION}

We usually advise patients to remain on anticoagulants for 3-6 months after operation. When we reviewed the clinical information we could not be certain how long $12(28 \%)$ of the 43 patients for whom follow up data were available were treated with anticoagulants. Twenty two $(71 \%)$ of the remaining 31 patients took warfarin for less than six months and a further two $(6 \%)$ took it for up to one year. One patient required long term anticoagulation for mitral valve disease and $\operatorname{six}(19 \%)$ continued warfarin out of personal preference or on the advice of their medical practitioner. Thus $24(77 \%)$ of the patients for whom information was available were not on long term anticoagulants. It seems likely that the proportion was similar in those for whom anticoagulant data were not available. Thus most survivors had only short courses of oral anticoagulants and, of these, one had a definite further pulmonary embolus as part of terminal illness and one otherwise fit individual may have had an acute minor embolism. At worst this represents a recurrence rate of $4 \cdot 6 \%$.

\section{Discussion}

The lung has an active fibrinolytic system and most pulmonary emboli resolve spontaneously ${ }^{67}$ over a few weeks. ${ }^{8-10}$ This spontaneous resolution makes it likely that many smaller emboli go undetected clinically. ${ }^{11}$ Clinically apparent episodes result in various syndromes, from "acute minor" to "acute massive" pulmonary embolism. ${ }^{12}$ Patients with little or no circulatory impairment after a pulmonary embolus can be treated symptomatically with anticoagulants such as heparin ${ }^{13}$ to reduce the likelihood of further emboli. Patients in this group are clearly not candidates for pulmonary embolectomy. Acute massive pulmonary embolism results in appreciable haemodynamic disturbance ${ }^{14} 15$ and carries a high mortality. ${ }^{16-18}$ Vigorous treatment for this group is mandatory but the choice of the most appropriate treatment has been the subject of some debate. There are two main alternatives-thrombolytic treatment and pulmonary embolectomy. Thrombolytic agents such as streptokinase, ${ }^{34}$ urokinase, ${ }^{1920}$ and recombinant tissue plasminogen activator (rt-PA) 2122 were effective in lysing pulmonary emboli and acted more quickly than heparin. ${ }^{34}$ Controlled and uncontrolled trials showed that mortality tended to be lower in patients treated
Gray, Morgan, Paneth, Miller with thrombolysis than with heparin. ${ }^{202324}$ These? differences did not reach statistical significance. None the less, a more rapid resolution of pulmonary emboli seems desirable because prolongedo haemodynamic disturbance can only cause harm, and흠 if further emboli develop their haemodynamic effect $\overline{\bar{n}}$. will be lessened if previous emboli have been $\bar{\Phi}$ partially removed. Thus the case for the urgent use of thrombolytic agents in patients with acute massive pulmonary embolism is powerful and our experience. supports this view. ${ }^{3524}$

Opinions on the place of pulmonary embolectomy vary considerably. Some claim that there are no indications for the operation ${ }^{1}$ while others believeor that prophylactic open pulmonary embolectomy can be justified. ${ }^{2}$ It has been argued that pulmonary embolectomy is seldom a practical procedure ${ }^{250}$ because few patients survive long enough for the procedure to be undertaken and that those who do are likely to survive anyway. ${ }^{1}$ There is some truth in this $\infty$ because although pulmonary embolectomy can be performed without cardiopulmonary bypass with acceptable results, ${ }^{26}$ most patients who require operation for acute massive pulmonary embolism in the United Kingdom are transferred to a regionato cardiothoracic centre. Inevitably some patients wilpo die before or during transfer but a significant numbero with acute massive pulmonary embolism wilk deteriorate some hours after the initial embolic episode $^{27}$ suggesting that although the risk of deatho declines with time it is not abolished. This has certainly been our experience; most patients in our series were transferred from other hospitals and were still severely compromised haemodynamically.

Although it has proved difficult to define thesef patients who are considered too ill to undergo a tria of thrombolytic treatment this does not deny thei需 existence and $32 \%$ of the patients in this series belonged to this group. Clearly decisions regarding operation have to be made for individual patients but we think that some patients are so severely? compromised haemodynamically by their massive pulmonary embolus that subjecting them to a trial of thrombolytic treatment is inappropriate and the should have pulmonary embolectomy. Also, everi. though the contraindications to thrombolytif treatment have relaxed with increasing experience in the use of these drugs, there is still a significan? number of patients for whom thrombolytic treatmen $\omega$ is believed to be inadvisable-they include patients who have recently undergone major operations of had a cerebrovascular accident, and those with active peptic ulceration or bleeding diatheses. Thes $\vec{e}$ patients, together with the few who deteriorat $\delta$ haemodynamically after starting thrombolyti treatment seem to be suitable candidates fof 
embolectomy. Unfortunately there has been no randomised trial of embolectomy and thrombolytic or anticoagulant treatment and there is unlikely to be one of sufficient size to be of value. This is because it is unethical to withhold embolectomy if a patient randomised to thrombolytic treatment deteriorates; this makes treatment failure a necessary end point as well as death. Also, few suitable patients with acute massive pulmonary embolism and significant haemodynamic impairment are likely to be recruited in any one centre. We therefore have had to turn to the published reports of clinical experience of this operation and make informed forecasts about likely benefit.

Many cases of pulmonary embolectomy have been reported since Trendelenburg's description in $1908{ }^{28} 29$ Recently these were reviewed by Del Campo who calculated an overall mortality of $40 \%$ for embolectomies performed on cardiopulmonary bypass. ${ }^{27}$ However, these results include early experiences where the reported mortality was often high. The subsequent reduction in mortality was at least partly related to the recognition that anaesthetic agents had profound hypotensive effects that were often fatal ${ }^{5730}$ and could be prevented by vasopressor agents.

Twenty one $(29 \%)$ of our series of 71 patients died in hospital. But mortality was considerably lower $(5 / 46,11 \%)$ in patients who had not sustained a cardiac arrest before operation than in those who had $(16 / 25,64 \%)$. We do not know how our patients would have fared if they had not had embolectomy. But we believe that it was of benefit.

Morbidity in patients undergoing pulmonary embolectomy was principally neurological. In most this damage was believed to have occurred before operation, usually as a result of a cardiac arrest. The outcome was good in patients who reached the operating theatre without needing external cardiac massage. Although most patients were not given long term anticoagulants the frequency of recurrent pulmonary emboli in the follow up period was low $(4 \cdot 6 \%)$. This accords with the view that long term anticoagulants are unnecessary ${ }^{31}$ and that for patients who have an isolated episode of massive pulmonary embolism procedures to plicate or place filters in the inferior vena cava are inappropriate. These procedures should probably be reserved for the few patients who have recurrent pulmonary emboli and in whom oral anticoagulation is either contraindicated or fails to prevent recurrence..$^{32} 33$

We use thrombolysis to treat acute massive pulmonary embolism unless such drugs are contraindicated or haemodynamic function is severely compromised. We believe pulmonary embolectomy provides an effective alternative treatment with an acceptable mortality in these two groups and in those who deteriorate on thrombolytic treatment.

\section{References}

1 Sautter RD, Myers WO, Ray JF III, Wenzel FJ. Pulmonary embolectomy: review and current status. Prog Cardiovasc Dis 1975;17:371-89.

2 Berger RL. Pulmonary embolectomy with preoperative circulatory support. Ann Thorac Surg 1973;16: 217-27.

3. Tibbutt DA, Davies JA, Anderson JA, et al. Comparison by controlled trial of streptokinase and heparin in treatment of life-threatening pulmonary embolism. Br Med J 1974;i:343-7.

4 Ly B, Arnesen H, Eie H, Hol R. A controlled clinical trial of streptokinase and heparin in the treatment of major pulmonary embolism. Acta Med Scand 1978;203:465-70.

5 Miller GAH, Hall RJC, Paneth M. Pulmonary embolectomy, heparin, and streptokinase: their place in the treatment of acute massive pulmonary embolism. Am Heart J 1977;93:568-74.

6 Fred HL, Lewis MJ, Alexander JK. Rapid resolution of pulmonary thromboemboli in man. An angiographic study. JAMA 1966;196:1137-9.

7 Sautter RD, Fletcher FW, Emanuel DA, Lawton BR, Olsen TG. Complete resolution of massive pulmonary thromboembolism. JAMA 1964;189:948-9.

8 Dalen JE, Alpert JS. Natural history of pulmonary embolism. Prog Cardiovasc Dis 1975;17:257-70.

9 Dalen JE, Banas JS, Brooks HL, et al. Resolution rate of acute pulmonary embolism in man. $N$ Engl $J$ Med 1969;280:1194-9.

10 Chait A, Summers D, Krasnov N, Wechsler BM. Observations on the fate of large pulmonary emboli. Am J Roentgenology 1967;100:364-73.

11 Freiman DG, Suyemoto J, Wessler S. Frequency of pulmonary thromboembolism in man. $N$ Engl J Med 1965;272:1278-80.

12 Miller GAH. Pulmonary embolism. In: Weatherall DJ, Ledingham JGG, Warrell DA, eds. Oxford textbook of medicine, vol 2. 2nd ed. Oxford: Oxford University Press, 1987:355-60.

13 Barritt DW, Jordan SC. Anticoagulant drugs in the treatment of pulmonary embolism: a controlled trial. Lancet 1960;i:1309-12.

14 Turnier E, Hill JD, Kerth WJ, Gerbode F. Massive pulmonary embolism. Am J Surg 1973;125:611-22.

15 Gorham LW. A study of pulmonary embolism. Arch Intern Med 1961;108:418-26.

16 Rosenberg DM, Pearle C, McNulty J. Surgical treatment of pulmonary embolism. J Thorac Cardiovasc Surg 1964;47:1-16.

17 Murphy ML, Bulloch RT. Factors influencing the restoration of blood flow following pulmonary embolisation as determined by angiography and scanning. Circulation 1968;38:1116-26.

18 Soloff LA, Rodman T. Acute pulmonary embolism. II: Clinical. Am Heart J 1967;74:829-47.

19 Urokinase pulmonary embolism trial. Phase 1 results. JAMA 1970;214:2163-72. 
20 National Cooperative Study. Urokinase pulmonary embolism trial. Circulation 1973;47-48(suppl II): 1-108.

21 Verstraete M, Miller GAH, Bounameaux H, et al. Intravenous and intrapulmonary recombinant tissuetype plasminogen activator in the treatment of acute massive pulmonary embolism. Circulation 1988;77: 353-60.

22 Goldhaber SZ, Vaughan DE, Markis JE, et al. Acute pulmonary embolism treated with tissue plasminogen activator. Lancet 1986;ii:886-9.

23 Hirsh J, Hale GS, McDonald IG, McCarthy RA, Pitt A. Streptokinase therapy in acute major pulmonary embolism. Effectiveness and problems. $\mathrm{Br} \mathrm{Med} J$ 1968;iv:729-34.

24 Miller GAH, Sutton GC, Kerr IH, Gibson RV, Honey $M$. Comparison of streptokinase and heparin in the treatment of isolated acute massive pulmonary embolism. Br Med J 1971;ii:681-4.

25 Alpert JS, Smith RE, Ockene IS, Askenazi J, Dexter L, Dalen JE. Treatment of massive pulmonary embolism: the role of pulmonary embolectomy. Am Heart $J$ 1975;89:413-8.
Gray, Morgan, Paneth, Miller $\stackrel{\frac{1}{\Phi}}{\stackrel{\infty}{\Phi}}$

26 Clarke DB, Abrams LD. Pulmonary embolectomy: a $25_{\mathrm{C}}^{\mathrm{+}}$ year experience. $J$ Thorac Cardiovasc Surg 1986;92:442-5.

27 Del Campo C. Pulmonary embolectomy: a review. Can J Surg 1985;28:111-3.

28 Trendelenburg F. Uber die operative Behandlung der $\overline{\bar{m}}$ Embolie der Lungenarterie. Arch Klin Chir 1908;86:686-700.

29 Sabiston D. Trendelenburg's classic work on the operative treatment of pulmonary embolism. AnnThorac Surg 1983;35:570-4.

30 Paneth M. Pulmonary embolectomy. An analysis of 12 cases. J Thorac Cardiovasc Surg 1967;53:77-83.

31 Petitti DB, Strom BL, Melmon KL. Duration of warfarin anticoagulant therapy and the probabilities of recurrent thromboembolism and hemorrhage. $\mathrm{Am}$. J Med 1986;81:255-9.

32 Greenfield LJ. Current indications for and results of $\overrightarrow{0}$ Greenfield filter placement. J Vasc Surg 1984;1:? $502-4$.

33 Brewster DC. Introduction to a symposium on transvenous vena cava interruption. $J$ Vasc Surg $\mathbb{\Phi}$ 1984;1:487-90. 